\title{
La representación cinematográfica de Eva Perón en los biopics: Evita, Eva Perón y Juan y Eva.
}

\section{Eva Perón's cinematographic representation in the biopics: Evita, Eva Perón and Juan y Eva.}

\author{
María Toscano Alonso \\ http://dx.doi.org/10.12795/AdMIRA.2017.01.03
}

\section{RESUMEN}

Eva Perón ha sido una de las mujeres más relevantes en el ámbito político mundial del pasado siglo, su persona se ha llevado a la gran pantalla en varias ocasiones y por ello cabe indagar en cómo es la representación que se ha hecho de ella. Para ello, tomando como referencia la Teoría Fílmica Feminista y la Teoría Narrativa, hemos realizado un análisis de la representación de Eva Perón en cuanto en tanto personaje y los aspectos de su vida que la rodean en los tres filmes del corpus: Evita, Eva Perón y Juan y Eva.

\section{PALABRAS CLAVE}

Eva Perón, representación femenina, biopic, mujer en la historia, cine biográfico, Evita.

\begin{abstract}
Eva Perón has been one of the most relevant women in the world political ambit of the past century, she has been taken to the big screen in several occasions and for this reason is pertinet to investigate how is the representation that has been made of her. For this, taking as reference the Feminist Film Theory and Narrative Theory, we have realized an analysis about the representation of Eva Peron as both a character and the Eva Perón life's moments that surround her in the three films of the corpus: Evita, Eva Perón and Juan y Eva.
\end{abstract}

\section{KEYWORDS}

Eva Perón, female representation, biopic, women in history, biographical pictures, Evita. 


\section{Introducción}

El cine es un medio muy popular en la sociedad (Ministerio de Educación, Cultura y Deporte, 2015: 17-18) y ello le otorga una gran responsabilidad a la par que puede ser peligroso debido a que los mensajes que se transmiten a través del cine llegan a una gran cantidad de personas. En algunas ocasiones los espectadores y espectadoras son conscientes de los mensajes y valores que subyacen en los textos fílmicos, sin embargo, existen los que no se dan cuenta de todo lo que la película le está diciendo y eso supone un acercamiento poco o nada crítico por su parte, lo que puede dar lugar al aprehendimiento de lo que el filme transmite. Por lo tanto, podemos decir que el cine es un de agente socializador, estos agentes son los que "se encargan de transmitir modelos y pautas de comportamiento; son muy diversos y actúan en función de una serie de normas y de conductas alrededor de las que suele producirse un consenso entre los diferentes ámbitos de la sociedad" (Pallarés Piquer, 2014: 233).

Por ello, debería prestarse atención a los contenidos ya que pueden promover el odio hacia grupos de diversa índole. En esta investigación nos vamos a centrar en lo que respecta a la igualdad de género ya que, como bien señala Elena Galán Fajardo, “los estereotipos de género están tan interiorizados en nuestra cultura, que se transmiten a menudo de un modo indirecto y precisan análisis profundos y elaborados para poder ser detectados, corregidos y adaptados a las nuevas circunstancias sociales" (2007: 236). Para poder cambiar estos estereotipos y los mensajes perjudiciales que se promueven, debemos primero encontrar cuáles son y cómo se reproducen en sus diferentes formas dentro del cine.

Entre la cantidad de obras y géneros cinematográficos que encontramos en la actualidad, hemos decidido detenernos en las películas biográficas, éstas han estado presentes desde los inicios de la cinematografía, no obstante, son escasos los estudios sobre las mismas. Este género, ligado a los estudios feministas, supone un número muy limitado de análisis y reflexiones. Consideramos relevante hacer un estudio que los unifique debido, no sólo a su escasez, sino también a la importancia de este cine en concreto, ya que al estar basado en la Historia suele ser menos cuestionado y, por tanto, tomado como verdadero.

Esta inquietud, sumada a la que surge al observar el papel al que han sido relegadas las mujeres en la Historia, plantea una nueva cuestión relativa a la representación cinematográfica de aquellas que han tenido presencia y relevancia histórica. Nuestra intención al estudiar la representación de Eva Perón es observar qué aspectos de su vida son llevados al cine para así poder determinar qué se 
cuenta sobre ella en los biopics.

\section{Corpus}

María Eva Duarte de Perón, también conocida como Eva Perón o Evita, es relevante por su papel en la política. Luchó por los derechos de los trabajadores y de la mujer, y entre sus logros se le atribuye haber conseguido la igualdad política entre hombres y mujeres. De Eva Perón se visionarán y analizaran las siguientes películas:

Tabla 1.

\begin{tabular}{|l|l|l|}
\hline Título & Director/a & Año \\
\hline Evita & Alan Parker & 1996 \\
\hline Eva Perón & Juan Carlos Desanzo & 1996 \\
\hline Juan y Eva & Paula de Luque & 2011 \\
\hline
\end{tabular}

Películas que conforman el corpus.

\section{Objetivos}

El objetivo principal de esta investigación es dilucidar cómo es representada Eva Perón en los biopics, qué tipo de personaje se crea en torno a su figura, así como observar qué aspectos de su vida son mostrados en los mismos. Estableceremos los acontecimientos que fueron relevantes en el devenir de su vida y si están o no presentes en los filmes.

\section{Estado de la cuestión}

Cuando queremos acercarnos al cine biográfico encontramos que la bibliografía específica al respecto aún es escasa, siendo éste todavía un género difuso. También son limitados los textos sobre la representación femenina en el biopic desde una perspectiva de género, aunque en los textos sobre cine biográfico hallamos algunos apartados dedicados a dicha cuestión y existen también algunos artículos y capítulos de libros sobre los que nos detendremos más adelante.

Sobre la representación de Eva Perón se conoce Eva Perón. Cuerpo, género, nación de Valeria Grinberg Pla, sin embargo, el acceso a dicho título ha resultado imposible, sí hemos podido acceder a una reseña del libro realizada por Magdalena Perkowska (2014). De ésta, entendemos que el estudio de Eva Perón se centra en el imaginario que se construye de ella mediante las diversas representaciones en el cine, la ópera o la literatura, relacionando la representación del cuerpo con la identidad nacional y la política. 


\section{Preguntas de investigación}

- ¿Es Eva Perón representada cinematográficamente en función a los logros por los que es conocida?

- ¿Es la protagonista de los filmes y se demuestra su valía o aparece a la sombra de un personaje masculino?

- ¿Se muestran aspectos de su vida en solitario o siempre está vinculada a un hombre?

- ¿Con qué tipo de roles es representada?

- ¿Es un personaje complejo que muestra un arco de evolución?

- ¿Es el sujeto de la historia y es mostrada de forma activa?

\section{Teoría Fílmica Feminista}

La Teoría Fílmica Feminista surge en los años 70 con la premisa de "hacer visible lo invisible" (Kuhn, 1991: 87), con ello se refiere a "observar [1]a posición de la mujer como miembro de una plantilla del sistema de producción cinematográfica o como elemento narrativo, expuesto a la mirada a través de los créditos o a través de los personajes" (Guarinos, 2008: 104). De las teóricas de esta corriente vamos a tomar como punto de partida a Teresa de Lauretis y su texto Alicia ya no: Feminismo, semiótica, cine (1992).

"La representación de la mujer como espectáculo (...), omnipresente en nuestra cultura, encuentra en el cine narrativo su expresión más compleja y su circulación más amplia” (De Lauretis, 1992: 13). Debido a esta afirmación, podemos decir que el cine tiene una gran responsabilidad en cuanto a aquello que muestra ya que a través de éste se crea un imaginario social sobre las figuras representadas, dando lugar a la posibilidad de contribuir en el fomento de determinadas actitudes, debido a su carácter de agente socializador. Podemos decir que, "como seres sociales, las mujeres se construyen a partir de los efectos del lenguaje y la representación" (De Lauretis, 1992: 29), ambos utilizados y dominados por el patriarcado, ya que éste ha sido el poseedor del poder y, por tanto, de la palabra. "El cine y las películas interpelan a las mujeres lo mismo que a los hombres. Sin embargo, lo que distingue a las formas de esa interpretación está lejos de ser obvio" (1992: 29), a menudo la mujer toma la posición de objeto dentro del filme, el objeto que es mirado, tanto dentro como fuera de la pantalla, sin embargo, rara vez ocupa el lugar de sujeto que mira, este espacio está reservado para el hombre. Se crea entonces la relación mirada/imagen que corresponde a la relación hombre/mujer, es decir, "el cine dominante instala a la mujer en un particular orden social y natural, la coloca en una cierta posición del significado, la fija en una cierta identificación. Representada 
como término negativo de la diferenciación sexual, espectáculo-fetiche o imagen especular, en todo caso ob-scena (esto es, fuera de la escena)" (1992: 29).

En cuanto a la identificación, muy relacionada con lo anterior, Laura Mulvey (2001) plantea dos ideas. Por una parte, habla sobre la escopofilia, idea surgida de Sigmund Freud relativa al placer de observar a otros, en este caso a través de la pantalla. Por otra parte, trata la identificación que se produce a raíz del narcisismo y la construcción del ego ya que "el cine posee estructuras de fascinación suficientemente fuertes como para permitir pérdidas temporales del ego y, simultáneamente, reforzarlo" (Mulvey, 2001: 369), lo que lleva al espectador a identificarse con el personaje. A continuación, expone que la mujer se convierte en un elemento pasivo, debido a que "la mirada determinante del varón proyecta su fantasía sobre la figura femenina, a la que talla a su medida y conveniencia" (2001: 370).

\section{El biopic como género}

Las películas biográficas han estado presentes desde los inicios del cine, "casi trescientos biopics ${ }^{1}$ fueron producidos por los grandes estudios durante el período clásico de 1927-1960" (Custen, 1992: 3). Actualmente, encontramos una considerable cantidad de biopics (biographical pictures) que narran vidas e historias de diversa naturaleza y con distintos enfoques. Sin embargo, aunque estas películas estén en la historia del cine, cabe preguntarse: ¿Qué constituye al biopic como género?

Para George F. Custen "una película biográfica es la que representa la vida de una persona histórica, pasada o presente" (1992: 5). Por su parte, Javier Moral denomina el biopic como un "género borroso" (2001: 88) y cuestiona que la simple presencia de un personaje histórico convierta a un filme en un biopic; dice que es evidente la necesidad de éste pero no suficiente (2010: 12-13). Dennis Bingham afirma que "el biopic narra, expone y celebra la vida de un sujeto con el fin de demostrar, investigar o cuestionar su importancia en el mundo" (2010: 10). Por otro lado, Valentina Cucca va mostrando el proceso que le lleva a determinar lo que entiende por biopic:

\footnotetext{
El análisis de un género nos permite captar las dinámicas subyacentes como pone de relieve el pacto táctico entre quien cuenta la historia y quien la ve y escucha, la audiencia. Este contrato entre cineastas y audiencia se basa principalmente en la promesa de los primeros de decir algo nuevo sobre la matriz de algo conocido y familiar. En el caso de los biopics, historias de vidas reales de personajes más o menos conocidos (2011: 169).
}

Podemos decir que existe cierto consenso entre los autores a la hora de determinar el rasgo principal del biopic. Sin embargo, tanto Custen como Moral, van a proponer otros elementos que consideran 
característicos del género. Moral, Basándose en textos de Metz y Barthes, propone algunos rasgos para determinar el biopic, entre ellos: que el relato biográfico es cerrado (no excede el tiempo de la vida del personaje), la frecuencia del comienzo in media res o la ausencia de enunciador, y por lo tanto, supuesta objetividad, entre algunos otros elementos que, si pensamos en conocidos biopics, no siempre se cumplen y por lo tanto es arriesgado considerarlos ragos definitorios del género.

Custen contempla que los componentes narrativos que van a caracterizar al biopic como género son los elementos de la vida de la persona/personaje, dice que si al comienzo de la película se muestra la familia o el personaje mostrando su talento o comportamiento que le hará famoso, estamos ante una diferencia discursiva que podemos considerar una característica (1992: 67). No podemos negar que la familia o aquello que hace conocido a un personaje estará presente ya que forma parte de su vida y tiene gran peso en ella, sin embargo, no siempre podremos encontrar que estos elementos aparecen al inicio del filme.

A la vista de la ausencia de la definición de rasgos comunes de forma evidente en todas las obras, el elemento que pensamos indispensable y se cumple en todos los casos es que "en la narración biográfica el personaje desempeña claramente el rol Sujeto, definido no por casualidad por Greimas como un verdadero actante del espectáculo" (Moral, 2010: 82). Así pues, es el protagonismo de un personaje histórico el que da al filme el carácter biográfico, ya que cada obra que contenga este elemento puede estar inscrita en otro u otros géneros a su vez y ser contada de diversas maneras.

\subsection{Panorámica de los biopics sobre mujeres}

La Historia ha marginado y ocultado de forma asidua el papel de las mujeres en el desarrollo y evolución de la misma. Esto, ligado al bajo porcentaje de personajes femeninos en el cine, da como resultado que haya "casi dos veces y media más biografías masculinas que femeninas. Además, la mayor parte de las biografías femeninas son de artistas y amantes" (Custen, 1992: 65-66). El autor señala que estas mujeres son representadas como un objeto de la mirada masculina.

Un gran porcentaje de los biopics sobre mujeres son relativos a la realeza, un $17 \%$ vemos en el texto de Custen (1992) -no se encuentran datos de si el porcentaje es mayor o menor en la actualidad. En esta representación, “a menudo, la figura real femenina debe elegir entre su corazón y su compromiso "profesional" para el Estado. La mera propiedad hasta del deseo sexual se toma a menudo, por los hombres, como un signo de debilidad" (105).

Con respecto a las artistas, vemos que "en su proyección siempre aparece un hombre, marchante, 
amante o amigo, del cual, según el discurso fílmico, dependió su felicidad. No tuvieron demasiados momentos de plenitud y el arte fue la válvula de escape a tanto sufrimiento" (Camarero Gómez, 2011: 60). En el caso de la política, existe "una invisibilización del papel de la mujer que deja al descubierto un cine que mantiene aún una poderosa mirada patriarcal y androcéntrica sobre la realidad" (Herrera y López, 2013: 63). Con respecto a esto último debemos detenernos en que tan solo se han llevado a la gran pantalla como protagonistas a dos de las cincuenta presidentas electas de la historia (2013: 64); además, las primeras damas que han sido representadas siempre dependen de la figura masculina y renuncian a sus carreras profesionales, limitándose a ser compañía del Presidente.

Bingham (2010) asegura que a menudo los personajes femeninos en los biopics han sido víctimas y aquello que las hace exitosas siempre aparece rodeado de conflictos y tragedia, también, con frecuencia, se muestra a estas mujeres como trastornadas por diversas circunstancias (2010: 217). Conforme han ido avanzando los tiempos, se han ido incorporando nuevas biografías de diversa índole a la cinematografía, una de ellas es Erin Brockovich (Steven Soderbergh, 2000), que muestra a una mujer fuerte y luchadora, a la que Bingham le dedica un capítulo afirmando que no aparece victimizada. Sin embargo, pone de relieve que "como película biográfica sobre una mujer es una excepción que confirma la regla" (2010: 334).

\section{Metodología}

"El análisis narrativo del cine es la rama más reciente de la investigación semiótica al emerger de las iniciativas críticas que redefinieron la teoría fílmica en los años setenta”, este tipo de análisis “persigue desentrañar las relaciones aparentemente «motivadas» y «naturales» entre el significante y el mundo de la historia con el fin de revelar el sistema más profundo de asociaciones culturales y relaciones que se expresan mediante la forma narrativa" (Stam, Borgoyne y Fitterman-Lewis, 1999: 91). Dentro de esta vertiente, encontramos que se contemplan diversos estratos dependiendo de su trabajo narrativo, entre ellos tenemos las esferas de acción. Esta noción de esferas de acción ${ }^{2}$ surge en un inicio del trabajo de Vladimir Propp, éste, en Morfología del cuento (1981), extrae treinta y una funciones comunes a todos los personajes de los cuentos que analiza, así como siete roles: “el antagónista (el agresor), el donante, el auxiliar, la princesa o su padre, el mandatario, el héroe y el falso héroe" (1981: 184).

En función al texto de Propp surge el modelo actancial de A.J. Greimas, donde separa los actantes en seis; "el actante es una unidad autónoma dentro del relato y que tiene capacidad de acción" 
(Velázquez, 2011: 244), sobre esto volveremos más adelante en el apartado de la metodología. Estas ideas sobre los actantes, las funciones y los roles, constituyen las esferas de acción, como decíamos antes, y es este aspecto el que analizamos en el actual trabajo, centrándonos, casi de manera exclusiva, en los personajes protagonistas de los filmes que configuran las esferas de acción, a partir de sus funciones, sus roles y otros aspectos añadidos a los planteamientos de Propp y Greimas.

Cabe señalar que en el análisis narratológico se produce una interpretación del texto narrativo, "es posible a partir de una descripción («el texto está construido así») atribuirle un significado al texto («el texto significa esto»). Una interpretación no es nunca más que una propuesta («creo que el texto significa esto»). Si una propuesta pretende ser aceptada, debe estar bien fundada («creo sobre la base de los datos presentados que el texto significa esto»)" (Bal, 1985: 17). Como herramienta para fundamentar nuestra propuesta tenemos la Teoría Fílmica Feminista así como la base biográfica sobre Eva Perón.

La metodología concreta de la que aquí vamos a valernos consiste en el análisis de las esferas de acción de la Narrativa Audiovisual. Para ello, utilizaremos la rejilla de análisis de personajes desarrollada por Virginia Guarinos y utilizada en Construcción de la masculinidad en los personajes de ficción seriada española de televisión (Guarinos, 2013). Esta rejilla se compone de tres niveles de análisis similares a los que proponen Casetti y Di Chio en Cómo analizar un film (2003): personajes desde el nivel del relato (como persona), el nivel de la historia (como rol) y el nivel de la fábula (como actante).

Además, a la hora de determinar los roles, vamos a valernos del artículo "Mujer y cine" (Guarinos, 2008). En cuanto al nivel de la fábula, debemos destacar el esquema actancial de Greimas; cada actante es el que realiza una función. El autor separa las funciones dentro de la narración en seis, dando lugar así a los seis actantes: sujeto (realiza la acción y tiene relación con un objeto), objeto (recibe la proyección del sujeto), destinador (motiva al sujeto a cumplir su objetivo), destinatario (recibe las acciones del sujeto), ayudante (ayuda al sujeto a conseguir el objeto) y oponente (dificulta al sujeto conseguir el objeto).

Figura 1.

$\begin{array}{cc}\text { Destinador }- & \text { Objeto } \rightarrow \text { Destinatario } \\ \uparrow & \uparrow \\ \text { Ayudante } \rightarrow & \text { Sujeto } \leftarrow \text { Oponente }\end{array}$

Esquema actancial. Semántica estructural (Greimas, 1987: 276). 
Tabla 2.

REJILLA DE ANÁLISIS DE PERSONAJES

FICHA TÉCNICA

Nombre:

Nacionalidad:

Carácter principal o secundario:

Carácter protagonista o antagonista:

Película:

Año:

NIVEL DEL RELATO. PERSONAJE COMO PERSONA

\begin{tabular}{|c|c|c|c|c|}
\hline & Edad & $\begin{array}{l}\text { Rasgos indiciales } \\
\text { (Apariencia } \\
\text { física) }\end{array}$ & $\begin{array}{l}\text { Rasgos artifactuales } \\
\text { (Vestimenta, } \\
\text { ademanes, forma de } \\
\text { hablar...) }\end{array}$ & Transformaciones \\
\hline \multicolumn{5}{|l|}{ Iconografía } \\
\hline & Comportamiento & Relación & $\begin{array}{l}\text { Pensamientos, estados } \\
\text { anímicos, emociones, } \\
\text { valores, sentimientos }\end{array}$ & Evolución \\
\hline \multicolumn{5}{|l|}{ Psicología } \\
\hline & Clase social & Nivel cultural & Nivel económico & Amigos/familia \\
\hline \multicolumn{5}{|l|}{ Sociología } \\
\hline & Homo & Hetero & $\mathbf{B i}$ & $\begin{array}{l}\text { Trans/trav } \\
\text { (personaje-actor) }\end{array}$ \\
\hline Sexualidad & & & & \\
\hline
\end{tabular}

NIVEL DE LA HISTORIA. PERSONAJE COMO ROL

\begin{tabular}{|l|l|l|l|l|l|}
\hline Rol & Fijo & Eventual & Fijo-eventual & Episódico/ serial & Motivaciones y acciones \\
\hline & & & & & \\
\hline
\end{tabular}

NIVEL DE LA FÁBULA. PERSONAJE COMO ACTANTE

\begin{tabular}{|l|l|l|l|l|}
\hline & Fijo & Eventual & Fijo-eventual & Episódico/serial \\
\hline Sujeto & & & & \\
\hline Objeto & & & & \\
\hline
\end{tabular}




\begin{tabular}{|l|l|l|l|l||}
\hline Destinador & & & & \\
\hline Destinatario & & & & \\
\hline Ayudante & & & & \\
\hline Oponente & & & & \\
\hline
\end{tabular}

OTRAS ANOTACIONES DE INTERÉS:

PERSONAJE ESPEJO DE OTRO EN OTRAS PELÍCULAS:

Rejilla de análisis de personajes.

Para desarrollar la tabla de análisis de Eva Perón, el texto principal en el que nos hemos basado ha sido Evita (1994), de Marysa Navarro, una biografía con un trabajo de documentación muy extenso y usado en diversas investigaciones sobre la primera dama argentina. Además, La razón de mi vida, autobiografía de Eva, ha sido útil para entender cómo se veía a sí misma y que elementos de su vida destaca ella. Se ha contado también con el apoyo de la Tesis de Susana Rosano, "Rostros y máscaras de Eva Perón: imaginario populista y representación (Argentina 1951-2003)” y el artículo de Ana Valeria Caroglio "De mitos e historia: Eva Perón”.

Tabla 3 .

\begin{tabular}{|c|c|}
\hline \multirow{2}{*}{\multicolumn{2}{|c|}{$\begin{array}{l}\text { REJILLA DE ANÁLISIS DE } \\
\text { MARÍA EVA DUARTE DE PERÓN }\end{array}$}} \\
\hline & \\
\hline Elementos de relevancia & Cómo aparecen \\
\hline $\begin{array}{l}\text { Juan Duarte. Infidelidad, muerte influencia del } \\
\text { acontecimiento en su futuro }\end{array}$ & \\
\hline Pasado de pobreza & \\
\hline Traslado de Junín a Buenos Aires & \\
\hline Transcurso de los 15 a los 20 años en Buenos Aires & \\
\hline Trabajo como actriz en teatro, cine y radioteatro & \\
\hline Conoce a Perón (Gala benéfica por el terremoto) & \\
\hline
\end{tabular}




\begin{tabular}{|l|l|}
\hline Comienzo de la relación & \\
\hline $\begin{array}{l}\text { Está presente en reuniones de Perón con otras figuras } \\
\text { políticas importantes }\end{array}$ & \\
\hline Vida durante estancia de Perón en prisión & \\
\hline Actos en relación al 17 de Octubre & \\
\hline Casamiento con Perón & \\
\hline Deja la actuación, dedicación a la política & \\
\hline Viaje a Europa & \\
\hline Sufragio femenino en Argentina & \\
\hline Partido Peronista Femenino & \\
\hline Fundación Eva Perón & \\
\hline Rechazo de la vicepresidencia & \\
\hline $\begin{array}{l}\text { Comienza a estar débil hasta que recibe la noticia de } \\
\text { que tiene cáncer }\end{array}$ & \\
\hline La muerte de Eva & \\
\hline
\end{tabular}

\section{Otros apuntes:}

Rejilla de análisis ad hoc.

Para reforzar la metodología, se someterá cada película al test Bechdel -aplicado a numerosas películas de Hollywood para ver su nivel de patriarcalidad-, éste consiste en comprobar si en la película:

- Salen dos o más personajes femeninos juntos en la escena.

- Estos personajes femeninos hablan entre ellos.

- Su conversación no es sobre un hombre.

\section{Resultados}

María Eva Duarte de Perón (1919-1952), ha sido representada en varios medios y diversas ocasiones, si bien vamos a hacer hincapié en la representación cinematográfica de la actriz y Primera Dama de Argentina, existen libros, teatros e incluso una ópera -en la que luego se basó la película Evita-. En el texto de Marysa Navarro comprobamos que existen tanto admiradores, que elevan a Evita al nivel de Santa, como detractores que la demonizan, y en sus ideales radican las distintas versiones sobre su persona. Al estar tan intrínseca la política en la vida de Eva, es difícil encontrar textos que no hablen sobre ella desde un punto de vista que simpatice con las ideas del 
peronismo que se oponga a éstas. No obstante, no se puede negar, independientemente de ser peronista o antiperonista, que Eva dedicó muchos años de su vida a darlo todo por Perón y por el pueblo argentino.

Entre estas tres películas encontramos puntos comunes, como cabe esperar, pero también muchas diferencias. Por una parte, Evita, la película biográfica musical de Alan Parker y Eva Perón de Juan Carlos Desanzo, ambas de 1996, tienen a Eva como protagonista, mientras que Juan y Eva, de Paula de Luque (2010), como su propio título anuncia, tiene como protagonistas a ambos. En las dos primeras se abarca gran parte de los elementos relevantes de las biografías de Eva, sin embargo, la más reciente, como veremos a continuación, abarca desde 1944 hasta el 17 de octubre de 1945, centrándose en mayor medida en la relación amorosa de Juan Domingo Perón y María Eva Duarte.

\subsection{La infancia de Eva}

Hija de Juana Ibarguren y Juan Duarte, Eva nació en Los Toldos el 7 de mayo de 1919. La relación entre sus progenitores era extramatrimonial, él tenía mujer e hijos en Chivilcoy, donde ostentaba un cargo político. El padre ausente de Eva falleció en 1926, al recibir la noticia, la familia Duarte Ibarguren acudió a su velatorio en Chivilcoy. Hecho que aparece en Evita y Eva Perón, aunque de forma algo diferente: en la primera, no dejan pasar a la familia, Eva se escapa y entra en la iglesia; en la segunda, la familia legítima de Juan Duarte llega a un acuerdo para permitir que Juana y sus hijos entren a despedirse de él. En ambos casos se observa la humillación a la que se vio sometida Eva con tan solo siete años. Por su parte, en Juan y Eva, no es el velatorio sino la relación entre Juana y Juan la que aparece, en este caso a través de una conversación entre Eva y Perón.

En 1930, la familia Duarte Ibarguren se traslada a Junín, el centro urbano más cercano a su anterior residencia. Acontecimiento que no se muestra, así como la necesidad económica que llevo a Juana a convertir su casa en una pensión y dar de comer a los trabajadores. Se apela a la situación de pobreza que vivió Eva en dos de los filmes. En Evita vemos cómo Eva trata de salir de Junín e ir a Buenos Aires, en la canción que se interpreta en dicha escena, Evita -interpretada por Madonnaexpresa su ansia por pertenecer a la élite y tener lujos. Por su parte, en Eva Perón, Eva -en este caso encarnada por Esther Goris- hace referencia a su pasado y señala las numerosas ocasiones en las que ha sido cuestionada debido a su procedencia humilde. En ambos filmes vemos a Eva identificarse con el pueblo y los pobres en sus discursos, lo cual tiene relación con su pasado y sirve para comprender cómo florece en ella la preocupación por la injusticia social al identificarla a ella misma con dicha situación; "los pobres creen que la miseria que padecen es natural y lógica. Se 
acostumbran a verla o a sufrirla como es posible acostumbrarse a un veneno poderoso. Yo no pude acostumbrarme al veneno y nunca, desde los once años, me pareció natural y lógica la injusticia social" (Perón, 1951: 16). Por último, en Juan y Eva-donde es Julieta Díaz quien interpreta a Eva-, es una conversación entre Perón y Ávalos la que deja ver levemente el pasado de ella sin muchos detalles.

\subsection{Desde el traslado a Buenos Aires hasta el terremoto de San Juan}

En lo que respecta a la marcha de Eva de Junín, las versiones biográficas difieren. Navarro expone las dos teorías más repetidas:

Las circunstancias que rodean su partida son todavía muy confusas y las versiones al respecto son múltiples. La más difundida, la haría dejar Junín en compañía del cantante de tangos Agustín Magaldi, el cual la habría llevado al pasar por esa ciudad durante una gira, quedando implícito que Evita se habría escapado con él. Otra versión, ligeramente distinta, la describe yéndose con Magaldi y con su mujer, pues ésta viajaba con él, pero con el permiso de doña Juana (Navarro, 1994: 31).

La primera versión es la que aparece en Evita, donde vemos a una Eva de 15 años insistente en su afán por abandonar Junín para hacerse actriz tratando de convencer a Agustín Magaldi, con el que mantiene relaciones sexuales, para que la lleve con él a la capital argentina; es una vez allí cuando Eva descubre que él está casado. En Juan y Eva no se dice cómo llegó a Buenos Aires, sí se menciona, por el contrario, en Eva Perón cuando mantiene una conversación con Paco Jamandreu y ella hace referencia a los insultos que se han proferido en su contra, entre ellos algunos referidos a su relación con Magaldi. Sin embargo, "según Erminda, Evita de ninguna manera se habría atrevido a irse sin el permiso de su madre. Doña Juana se opuso tenazmente a los deseos de Evita durante un tiempo, hasta que un día fue con ella a Buenos Aires y la acompañó a Radio Nacional” (Navarro, 1994: 31). Por lo tanto, este acontecimiento continúa siendo una incógnita.

Una vez que Eva llegó a Buenos Aires, pasaron un par de años hasta que consiguió incorporarse en una compañía e ir de gira por el interior del país, anteriormente realizó trabajos sin mucha transcendencia. Se dice que fueron tiempos difíciles para la aún menor de edad Eva Duarte, el "teatro argentino atravesaba una crisis profunda, acentuada por las condiciones económicas que afectaban al país" (Navarro, 1994: 37). A este respecto, en Evita, vemos la llegada de Eva a Buenos Aires junto a Magaldi, después, se va progresivamente con diferentes hombres que la ayudan a ascender en su carrera como actriz. Referencia que de nuevo también vemos en Eva Perón, cuando Eva dice haber tenido amantes militares. En Juan y Eva solamente oímos a Eva en el programa 
radiofónico sobre mujeres influyentes, no se ve nada sobre su llegada a Buenos Aires.

\subsection{Cuando Eva conoció a Perón. Inicio de la relación}

Con motivo del terremoto del 15 de Enero de 1944, se celebró el día 22 del mismo mes un evento artístico benéfico para ayudar a las víctimas. Fue esté el día y el lugar en el que se conocieron Eva Duarte, que asistía como actriz, y Juan Domingo Perón, Ministro de Guerra y Secretario de Trabajo, además de vicepresidente. Este acontecimiento hizo posible que Eva comenzase su andadura para convertirse en quien llegó a ser; por eso, parece en las tres películas que nos ocupan: en Evita, ella acude con uno de sus amantes militares al que deja a un lado para acercarse a Perón, tras el evento se va con Juan y ella, cantando, le dice que deben estar juntos; en Eva Perón, cuando ella ya está enferma habla con Perón sobre los días felices, entonces, mediante un flashback, se les sitúa en el momento que se presentan; en Juan y Eva, Perón da un discurso sobre el terremoto, Eva levanta la mano e interviene, él le pregunta su nombre, tras las palabras de Juan, charlan de forma distendida junto a Mercante y Rita Molina.

La relación entre Eva y Perón comienza, no sin crear comentarios, rechazo y habladurías, el reflejo de esto aparece en los tres filmes, ninguno queda exento de llamar a Eva "puta" en algún momento, siendo tal vez Evita la más contundente en éste aspecto dedicando una canción a decir sobre ella que es una "puta", "peligrosa ramera" y "zorra", y tiene que entender "que la cama es su deber" (Parker, 1996: 00:54:29-00:57:59). En Juan y Eva es a través de un compañero de la radio que le comenta que algunos la llaman "puta, la mantenida de Perón” (De Luque, 2010: 00:45:4700:46:21). Finalmente, en Eva Perón, es Farrel, ex-presidente de Argentina, el que la llama "puta", pero también ella misma se llama así recordando en un par de ocasiones cómo la ven a ella los detractores del peronismo.

Encontramos un acontecimiento que tiene lugar en dos de los filmes y no aparece en ninguno de los textos utilizados, hablamos de cuando Eva, al inicio de su relación con Perón, acude a su casa y echa a la entonces novia del Coronel, que algunos medios identifican en Juan y Eva como su hija. En este caso, Eva acude a casa de Perón expresamente a echar a la joven sin que Perón esté allí. En Evita, vemos a Eva y Perón llegando a la casa y ella se adelanta para entrar en la habitación y decirle que ahora el trabajo que realizaba como novia de Perón lo hará ella. En ninguno de los filmes se dice su nombre. Es en el texto Blanca Luz Brum, una vida sin fronteras (2011), donde vemos el acontecimiento de la joven amante de Perón, identificada como María Cecilia Yurbel (Piñeyro, 2011: 153-155). Con respecto a Blanca, tan solo aparece en el filme de Paula de Luque, 
donde vemos su papel en torno al 17 de Octubre y la relación de ésta con Eva y Juan.

Por último, debemos mencionar la asistencia de Eva a las reuniones que Perón tenía con otros cargos políticos en su casa. Ésta parecía molestar a algunos de los presentes, como es el caso de Ávalos en Juan y Eva. Por otra parte, en el filme de Desanzo, es la propia Eva la que aparece reunida con diferentes personalidades.

\subsection{El 17 de octubre y los inicios de Eva en la política}

El día 17 de octubre de 1945 marcó un antes y un después en Argentina, así como en la vida de Eva. A raíz de la estancia en prisión de Perón durante ocho días, se convoca una huelga para el día 18 de octubre con el fin de conseguir la libertad de Juan Domingo Perón. Sin embargo, “el 17 de madrugada, en todo el país, miles de mujeres y hombres dejaron sus trabajos e invadieron las calles de la ciudad en ruidosas manifestaciones de apoyo a Perón" (Navarro, 1994: 90); ninguno de ellos se marchó hasta que Perón salió a hablar al balcón de la Casa Rosada. Este suceso es representado en todas las películas analizadas. En Evita, vemos a Eva como un componente relevante para que los hechos se dieran como se dieron: da discursos en la radio, llama al pueblo para que acuda a la huelga y se identifica como una "descamisada"3 más. Siguiendo con Eva Perón, no se muestra mucho más que a Farrel diciéndole a Perón que envíe a casa a toda la gente que está aclamándole en la plaza. Por último, en Juan y Eva, él le envía una carta a Eva desde la cárcel pidiéndole que hable con Mercante y los demás. No vemos a Eva tener mayor papel, sin embargo, sí aparecen Blanca, hablando con un gremio de mujeres, y Mercante con uno de hombres. La actuación de Eva en cuanto a los hechos acaecidos el 17 de octubre no está muy clara, si bien "ella nunca se atribuyó una actuación destacada en esos días" (Navarro, 1994: 99).

Cuatro días más tarde del acontecimiento que pondría a Perón en el centro del país, María Eva Duarte pasó a ser María Eva Duarte de Perón, el casamiento con Juan la posicionaría entonces como Primera Dama de Argentina. A partir de este momento ella se desprendió de su carrera artística y decidió unirse a la causa de Perón con toda su entrega. En Eva Perón podemos observar que se le atribuye a Juan la decisión de que Eva deje de actuar cuando le pide que sea su mujer.

Es ahora cuando Eva comienza a llevar a cabo una serie de acciones en relación con Perón, al principio de cara a las elecciones de febrero de 1946, más adelante, como apoyo del electo Presidente de Argentina. Acudía a diversos actos en favor de los trabajadores y los pobres, “además de visitar gremios, repartir ropa y de acompañar a Perón, desde mediados de julio Evita iba todos los lunes, miércoles y viernes por la mañana a la Dirección de Correos y Comunicaciones (...) atendía a todos los que buscaban obtener una entrevista con Perón, para impedir que continuaran 
desfilando por la Casa Rosada o la residencia presidencial” (Navarro, 1994: 112-113).

Poco después, en septiembre, Eva se instala en un despacho del Ministerio de Trabajo y Previsión Social, "desde ahí, su intermediación entre Perón y los descamisados fue de vital importancia para el presidente, consolidando sus funciones hacia 1948. Viajó a Europa en junio de 1947" (Caroglio, 2008:171). El evento europeo tan solo es narrado en Evita, se pone énfasis en que su visita no fue un éxito en el continente de forma general, sino en España particularmente.

\subsection{El voto femenino, el Partido Peronista Femenino y la Fundación Eva Perón}

"Por lo general, tanto la literatura peronista como la antiperonista atribuyen la sanción de la Ley 13.010 en gran parte a los esfuerzos de Evita” (Navarro, 1994: 148), esta ley otorgaba a las mujeres el derecho al voto, se promulgó el 23 de septiembre de 1947. Si bien se ve a Eva como la principal precursora de la misma, lo cierto es que "ella no jugó un papel decisivo en la aprobación de la medida. Emprendió la lucha por el voto al final de ésta, ya que las feministas argentinas habían tratado de obtener el sufragio desde principios de siglo" (Íbid.). Sin embargo, aunque en este aspecto a Eva se la mostrase como parte de la lucha feminista, lo que se conoce es que fue conservadora en cuanto a los ideales de género, quería igualdad en cuanto a los derechos políticos pero a su vez defendía que las mujeres "nacimos para constituir hogares. No para la calle” (Perón, 1951: 202). Muchas de las ideas de Eva con respecto al feminismo son contradictorias, pero sea como fuere apenas vemos referencias a la lucha por el sufragio femenino en los biopics. En la película de Desanzo, Eva reivindica su derecho al voto desde la cama, anunciando que va a votar aunque sea en el hospital. Por su parte, en el largometraje de Parker aparece el "Partido Feminista", encabezado por Eva Perón -partido que nunca llevó ese nombre sino el de Partido Peronista Femenino- que da discursos ante una gran cantidad de mujeres en pro del voto femenino pero siempre ensalzando la figura de Perón. El filme Juan y Eva, finaliza con el acontecimiento del 17 de octubre por lo que los hechos posteriores no aparecen.

En 1948 se crea la Fundación Eva Perón “como consecuencia de la amplitud que habían tomado las actividades de Evita en el campo social y de la necesidad de establecer un organismo con personería jurídica que las centralizara y controlara”. Al respectos, en Evita, aparece Eva tirando billetes a los pobres, además, en la canción correspondiente se dice que margina a los pobres porque sólo ayuda si ellos van a ella y que administra el dinero como quiere. En Eva Perón, ella dedicarse plenamente a la fundación. Al inicio del filme llega a casa y Perón le dice que la ve muy delgada, que no descansa y es debido al tiempo que pasa trabajando allí. 


\subsection{Candidatura a la vicepresidencia, antesala de la enfermedad}

En 1951 comenzaba la campaña electoral de cara a las elecciones de noviembre del mismo año. Por aquel entonces ya se había rumoreado la posible candidatura de Eva a la vicepresidencia. El 2 de agosto de 1951, “doscientos miembros del Comité Confederal de la CGT resolvieron pedir a Perón que aceptara la reelección” (Navarro, 1994: 227), además de la vicepresidencia de Eva, proponiendo así la fórmula Perón-Eva Perón. El pueblo argentino que apoyaba al peronismo, rápidamente salió a la calle apoyando la propuesta de la CGT. En ambos filmes, Eva Perón y Evita, se muestra la candidatura de Eva a la vicepresidencia, en cada una de ellas de diferente manera. En la película de Desanzo, Eva aparece muy insistente en la necesidad que supone para ella ser la vicepresidenta para dejar de ser juzgada y poder apoyar todos sus actos en el derecho que le profiere ostentar dicho puesto. Perón al principio aparece a favor de la idea, su deseo es tal para ser visto él como un dios junto a ella que es más odiada y relegada a demonio. Sin embargo, se da cuenta de que Eva no es manipulable y que se equivocó diciendo que sería fácil. En Evita, el evento pasa de forma fugaz, ella es presentada al cargo, el pueblo la apoya y rápidamente llegamos al momento determinante.

"Hacía más de un año que su salud era motivo de preocupación para sus allegados, pues no descansaba y trabajaba verdaderamente demasiado" (Navarro, 1994: 232). La falta de atención de Eva a su propia salud fue el desencadenante de un gran sufrimiento, teniendo que renunciar en agosto de 1951 a la vicepresidencia por este motivo. En Eva Perón ella no cree estar enferma, piensa que la oposición quiere eliminarla y le han provocado el malestar que siente. Sin embargo, Juan quien acaba dándole la terrible: Eva tiene cáncer. En el filme de Parker, Eva se desmalla tras un discurso, su hermano Juan se la lleva cogiéndola entre sus brazos. La vemos preocupada por el futuro y finalmente comunica al pueblo que tiene que rechazar la candidatura; se muestra triste por su país, porque siente que su cuerpo la abandona y por verse derrotada La preocupación por el abandono del cuerpo aparece también en el filme de Desanzo pero de una forma más violenta, Eva dice odiar su cuerpo siente que éste le está traicionando.

Los tratamientos a los que Eva se sometió para luchar contra el cáncer de útero no tuvieron buenos resultados, y pese a su rechazo insistente a ser operada tuvo que acceder finalmente a hacerlo. Tampoco la operación eliminó la enfermedad ni el sufrimiento. Eva ejerció su derecho al voto desde la cama y fue testigo del resultado de las elecciones, de nuevo en favor a Perón. Todos estos acontecimientos, exceptuando el voto, son mostrados en Eva Perón. En Evita sobre todo se nos 
muestra su enfermedad de forma rápida y breve. Finalmente, Eva falleció el 26 de julio de 1952. Todos los peronistas salieron a la calle a llorar su muerte. Evita comienza y termina con el velatorio de Eva al que el pueblo acude para despedirla.

\subsection{Eva como persona, rol y actante}

En primer lugar, vamos a ver cómo es el personaje como persona. Iconográficamente es representada de forma fiel a las imágenes que sobre ella se pueden encontrar; sus movimientos, su forma de vestir y su cambio físico debido a la enfermedad. No obstante, en Evita su pelo está teñido de rubio ya cuando conoce a Perón; podemos ver en el texto de Marysa Navarro que en ese momento Eva aún era morena (1994: 59). En Juan y Eva, al no llegar a la etapa en la que Eva enferma, no vemos ese cambio físico, que por contra es muy pronunciado en Eva Perón.

En relación a los aspectos psicológicos, en Evita vemos una mujer ambiciosa, ya desde su adolescencia se muestra amante del lujo, ese estilo de vida es su prioridad, para ello tendrá múltiples relaciones interesadas con el objetivo de ascender en su carrera de actriz, para finalmente casarse con Perón, que puede darle todo lo que desee. El personaje no muestra una gran evolución psicológica en este filme. En Juan y Eva, tenemos a una Eva con carácter, muy pasional, que se deja llevar por los sentimientos fácilmente, pero a la vez es capaz de defenderse y decir lo que piensa. La Eva del filme de Desanzo tiene las ideas claras, sabe lo que quiere y trabaja para conseguirlo, además, al igual que en la anterior, tiene un carácter fuerte y no se calla nada. Es una mujer entregada a su trabajo, al pueblo y a la causa de Perón. En flashbacks aparece más alegre ya que el paso del tiempo juega en su contra llevándola al sufrimiento y la frustración de no poder seguir luchando por aquello que defiende.

En Evita, vemos los cambios en su nivel social, se nos muestra su pasado humilde, proveniente de una clase social baja, y como pasa a estar entre la élite; no podemos saber su nivel cultural ya que no se menciona específicamente. Paula de Luque también hace hincapié en sus orígenes; culturalmente vemos que carece de conocimientos en materias políticas y judiciales (cuando pregunta qué es un habeas corpus). En Eva Perón, la protagonista difícilmente mantiene una relación social si la forma de pensar de la otra persona no es la misma que la suya.

En lo que respecta a la economía, vemos que Alan Parker plasma un cambio considerable en la situación del personaje. En Juan y Eva ella parece ser independiente, sale adelante con su trabajo como actriz radiofónica. Para finalizar, en Eva Perón, aunque su estatus social y económico sea 
alto, Eva se posiciona como una descamisada y dice ser una más con respecto al pueblo.

Por último, la sexualidad es en los tres caso heterosexual, se muestra de forma más activa con Perón en el filme de Paula de Luque, y más peyorativamente en Evita, donde podemos decir que la utiliza como intercambio a la hora de conseguir lo que quiere.

En cuanto al rol que desempeña Eva, encontramos los siguientes: en Evita es el de "ángel”, “de piel de cordero y lobo en su interior, da el perfil de la anterior [haciendo alusión al estereotipo de chica buena ${ }^{4}$ ] pero es la más peligrosa, puesto que en su falsedad es ambiciosa y capaz de cualquier cosa en beneficio propio" (Guarinos, 2008: 116). Los elementos característicos de esta construcción estereotípica aparecen en el personaje, siendo éste el rol que se ajusta de mejor manera. En Juan y Eva, asume el rol de "influenciadora", éste corresponde a "un personaje que «hace hacer» a los demás, encontrando en ellos sus ejecutores" (Casetti y Di Chio, 2003: 179); encontramos en Eva esta característica como la más definitoria ya que sus actos relacionados con persuadir o, simplemente, mandar a hacer algo a otro personaje, son los que más peso tienen en el personaje de Eva. Para finalizar, en Eva Perón, tenemos el rol de "guerrera", siendo este rol el de las mujeres que "anteponen la lucha a otras facetas personales. Suelen (...) renunciar a los hombres o renunciar a su condición de guerreras por un hombre" (Guarinos, 2008: 116), no renuncia por completo a los hombres, pero sí vemos que apenas ve a su marido porque ella pasa muchas horas trabajando. También encontramos algunos aspectos de la femme fatale, como la tendencia a la autodestrucción, que vemos cuando Eva recibe la noticia de que tiene cáncer, o las malas costumbres físicas que derivan en enfermedad.

En cuanto al sistema actancial, Evita sitúa a Eva como protagonista y sujeto de la acción, cuyo objeto es una vida de lujo y exitosa, esta vida la consigue a través de Perón que sería su ayudante. Sus oponentes son los antiperonistas, que tratan de poner trabas a la relación. En alguna ocasión Eva se convierte también en objeto ya que Perón la ve como una recompensa. En Juan y Eva, difícilmente puede ser catalogada como sujeto, ya que no está muy claro qué quiere el personaje aparte de estar con Perón. Si embargo, el personaje de Juan Domingo Perón si tiene ambiciones personales con relación a la política. Eva es protagonista, se nos muestran sus sentimientos y sus acciones, pero más como ayudante o destinadora de los deseos del protagonista masculino. Como oponente de Juan y Eva tendríamos a Ávalos. Y como otros ayudantes sumados a Eva, tendríamos a Blanca y Mercante. El sujeto de Eva Perón es ella y su deseo es obtener la vicepresidencia. Perón será, a la par, ayudante y oponente dependiendo del momento, pues vemos que él quiere que ella sea vicepresidenta pero le pone algunos obstáculos. La enfermedad será su mayor oponente y el 
pueblo puede ser visto como el destinador que motiva a Eva a querer ser vicepresidenta.

\subsection{Test de Bechdel}

El test de Bechdel, podemos comprobar, que es aprobado a duras penas en dos de los filmes: Eva Perón y Juan y Eva. En el primer caso, se da la conversación entre mujeres de las que sabemos el nombre cuando Eva y Guillermina Bunge de Moreno hablan sobre la beneficencia que finalmente Eva decide disolver al ver la actitud y el trato que recibe por parte de ésta. En el filme de De Luque, es en la escena en la que Eva acaba de ser agredida físicamente por unos viandantes antiperonistas; Eva se encuentra en la casa junto a Blanca y Pierina, éstas le preguntan si se encuentra bien, en cierto modo, podríamos incluso decir que es una conversación relacionada con un hombre debido a que es uno el que produce la agresión. También brevemente Eva habla con Margarita diciéndole que no sabe en qué día vive. Estos son los únicos momentos en los que conversan mujeres.

\section{Conclusiones}

Si nos detenemos en las preguntas de las que surge este estudio, podemos desentrañar diversos aspectos.

En primer lugar, nos preguntábamos si Eva es representada en función a sus logros; en dos de los filmes se cumple, aunque Evita muestre muchos aspectos de forma algo diferente a como encontramos en las biografías, no cabe duda de que aparece como Primera Dama de Argentina. En esta ocasión se hace un recorrido por casi todos los momentos relevantes en la vida de Eva. Del mismo modo que en Eva Perón, donde hay un mayor detenimiento en sus últimos años pero se muestran mediante flashbacks instantes concretos. Sin embargo, en Juan y Eva vemos que el eje de la narración es el inicio de la relación entre ellos, el filme transcurre desde que se conocen hasta que deciden casarse.

Aunando las dos cuestiones posteriores, hemos visto que aunque el personaje de Eva ocupe el lugar de protagonista en los tres casos, está vinculada en gran medida a personajes masculinos, principalmente a Juan Domingo Perón, si bien es cierto, no se ve eclipsada por él. Se muestran momentos de la vida de Eva en solitario, como su trabajo en la fundación, su lucha contra el cáncer o su pasado, tanto fuera de Buenos Aires como sus primeros años en dicha ciudad. Además, no podemos olvidar que aquello por lo que Eva se convirtió en una figura relevante en el ámbito político de Argentina tiene una relación directa con Perón. Sin embargo, de nuevo es Juan y Eva el filme que menos se detiene en Eva fuera de su relación con Perón y le otorga a este más peso como 
co-protagonista.

Los roles en los que se posiciona a los personajes tienen mucho peso a la hora de ver qué ideas se está transmitiendo sobre ellos. De los tres personajes analizados podemos extraer cuatro roles. En Eva Perón vemos dos roles, por una parte es de "guerrera", como decíamos, es una mujer que se ve definida por la lucha, presente en muchos aspectos de su vida. Este es un rol positivo que aleja al personaje femenino de los estereotipos relacionados con la debilidad o el sentimentalismo, y a su vez no "falifica" al personaje. Por otra parte tenemos el rol de "femme fatale", que en este caso está presente por las características negativas relativas a la autodestrucción producida por una entrega a otra causa, producida por la lucha que la convierte en guerrera y, en su estatus de femme fatale que se está autodestruyendo, reafirma dicha condición teniendo que luchar en este momento consigo misma, con su cuerpo. La suma de ambos roles da equilibrio al personaje, lo llena de matices y hace ver diferentes facetas de Eva Perón.

Encontramos el rol de "influenciadora" en el personaje de Juan y Eva, dando una idea de Eva como manipuladora. En último lugar, el “ángel”, es un personaje con una gran ambición y capaz de cualquier cosa para beneficiarse, además suele ser joven, de clase social y nivel cultural usualmente medio o bajo; es el rol que encontramos en Evita. En esta ocasión, la imagen que se transmite de Eva es la de una persona sin escrúpulos a la que solo le importa salir favorecida y conseguir lo que quiere sin importar el precio.

Tabla 4.

\begin{tabular}{|l|l|}
\hline Película & Roles \\
\hline Evita & Ángel \\
\hline Eva Perón & Guerrera y femme fatale \\
\hline Juan y Eva & Influenciadora \\
\hline
\end{tabular}

En cuanto a la complejidad de los personajes, tenemos: un personaje que no evoluciona en Evita, aparece como un personaje ambicioso desde el principio hasta el final cuyo único cambio es su posición social. Encontramos en Juan y Eva una evolución positiva, el personaje, al principio no confía en los demás, Eva es celosa y controladora, sin embargo, la relación con algunos personajes mejora por la evolución de ella que aprende a confiar en ellos. En Eva Perón, la evolución es negativa tanto física como psicológicamente, la enfermedad frustra sus sueños y eso hace que su forma de ser varíe y se dé por vencida, llegando a decir que odia su cuerpo porque la traiciona, y, posteriormente, derrumbándose. 
Por otra parte, encontramos que tanto en Evita como en Eva Perón, los personajes son sujetos y por lo tanto activos, tienen capacidad de acción. En Juan y Eva, sin embargo, tenemos un personaje activo pero no es el sujeto principal del filme, su es deseo estar con Juan, y eso la convierte en sujeto, pero no es el deseo de mayor peso del filme, tienen mayor relevancia los deseos políticos de Juan y ella toma parte como ayudante o destinadora.

Debemos hacer mención a algunas cuestiones que hemos observado. En Evita, Eva es cuestionada y se le da un trato negativo en casi todo momento; sobre todo por parte del narrador, el Che Guevara, que se posiciona contrario a ella y está presente en muchos momentos del filme, incitando al espectador a que se identifique con él. Además, los insultos hacia Eva relacionados con su sexualidad -es llamada "ramera", "puta” y "zorra" en varias ocasiones y filmes-y la insinuación de que es una "cazafortunas" están patentes de una forma u otra en todas las películas. También se nos muestra a Eva como un personaje celoso tanto en Evita como en Juan y Eva, resaltando un acontecimiento que, para encontrar su origen hubo que recurrir a una biografía ajena al personaje de Eva -nos referimos al momento en el que ella echa a la entonces novia de Perón de la casa de éste. Podemos afirmar que en estos dos filmes se trata la biografía de la argentina de una forma negativa y contribuye a la creación de un imaginario social sobre Eva Perón muy diferente al del filme de Desanzo, donde el personaje tiene más contrastes plasmando aspectos negativos y otros positivos. A grandes rasgos, las representaciones cinematográficas coinciden con las obras biográficas escritas que se han utilizado de cara al análisis. Existen algunas discrepancias pero son de escasa relevancia. Quizás la más subrayable está relacionada con la ausencia en los textos escritos del acontecimiento, anteriormente comentado, entre Eva y María Cecilia.

Para finalizar, si retomamos el asunto de las características de las biografías audiovisuales, podemos decir que en las películas analizadas encontramos diferentes estructuras y géneros, el único elemento común es el personaje de Eva y algunos acontecimientos relacionados con la vida de la misma, ya que ni siquiera aparecen los mismos acontecimientos aún siendo la misma persona el centro de los filmes. Podemos confirmar, por lo tanto, que no existen estructuras narrativas fijas en el género así como el recurso de otros elementos cinematográficos de forma estable. En cuanto a la característica que menciona Custen, vemos que en el caso de Juan y Eva no existe un comienzo que muestre la familia ni el talento que hace famosa a la persona, el filme comienza con Eva siendo actriz, aspecto vital que no está directamente ligado con su relevancia histórica como Primera Dama de Argentina. 
Tabla 5.

\begin{tabular}{|l|l|}
\hline Película & Estructura, género y presencia o no de narrador \\
\hline Evita & Estructura: circular \\
& Género: musical, biográfico \\
& Narrador: sí \\
\hline Eva Perón & Estructura: no lineal (uso de flashbacks) \\
& Género: drama, biográfico \\
& Narrador: no \\
\hline Juan y Eva & Estructura: lineal \\
& Género: drama, romántico, biográfico \\
& Narrador: no \\
\hline
\end{tabular}

Estructuras, géneros y presencia o ausencia de narrador en los biopics.

\section{Notas}

1. Cursiva propia en todas las ocasiones que aparece "biopic" en una cita.

2. "Podemos indicar que numerosas funciones se agrupan lógicamente según determinadas esferas. Estas esferas corresponden a los personajes que realizan las funciones. Son esferas de acción” (Propp, 1981: 91).

3. "Descripción de tono peyorativo con que la oposición caracterizó a los que manifiestan su adhesión a Perón” (Navarro1994: 92-93). Según la RAE: “2. adj. despect. Dicho de una persona: muy pobre, desharrapada". Finalmente los mismos peronistas se hicieron con el término para llamarse a sí mismos, “descamisado es el que se siente pueblo” (Perón, 1951: 85).

4. "Lo es porque acepta el sistema, es sufridora, ingenua y conformista. Suele ser joven, pero discretamente hermosa y generalmente de clase social y nivel cultural medio-bajo. Su aspiración es ser feliz con un buen esposo toda la vida" (Guarinos, 2008:116).

\section{Referencias bibliográficas}

Bal, M. (1985). Teoría de la narrativa (una introducción a la narratología). Madrid: Cátedra.

Bingham, D. (2010). Whose lives are they anyway?: The biopic as comptemporary film genre. New Brunswick: Rutgers University Press.

Camarero Gómez, M.G. (2011). Ellas no bailan solas: mujeres artistas, en Camarero Gómez, M.G. (Ed.). Vidas de cine. El biopic como género cinematográfico. Madrid: T\&B Editores; 41-60.

Caroglio, A.V. (2008). De mitos e historia: Eva Perón. Revista Confluencia, 7; 165-191.

Casetti, Francesco \& Di Chio, Federico (2003). Cómo analizar un film. Barcelona, Ediciones Paidós. 
Cucca, V. (2011). Biopics as Postmodern Mythmaking. Akademisk Kvarter, 2; 166-180.

Custen, G. (1992). Bio/Pics: how Hollywood constructed public history. New Brunswick: Rutgers University Press.

De Lauretis, T. (1992). Alicia ya no. Feminismo, semiótica, cine. Madrid: Cátedra.

Galán Fajardo, E. (2007). Construcción de género y ficción televisiva en España. Comunicar, 28; 229-236.

Greimas, A.J. (1987). Semántica estructural. Investigación metodológica. Madrid: Editorial Gredos. Guarinos, V. (2013). Hombres en serie. Construcción de la masculinidad en los personajes de ficción seriada española de TV. Madrid: Fragua.

Guarinos, V. (2008). Mujer y cine, en Los medios de comunicación con mirada de género. Instituto Andaluz de la Mujer; 103-120.

Herrera, S. \& López, S. (2013). Mandatarias de cine: mujeres y política en el séptimo arte. Pueblos, $55 ; 62-65$.

Ministerio de Educación, Cultura y Deporte (2015). Encuesta de hábitos y prácticas culturales en España 2014-2015. Síntesis de resultados. Secretaría general técnica, subdirección general de documentación y publicaciones.

(http://www.mcu.es/culturabase/pdf/SINTESIS_DE_RESULTADOS_EHPCE_2014-2015.pdf)

Moral, J. (2010). Representación cinematográfica del artista plástico y biopic. Universitat Politècnica de València.

Mulvey, L. (2001). Placer visual y cine narrativo, en Wallis, B. (Ed.). Arte después de la modernidad. Nuevos planteamientos en torno a la representación. Madrid: Akal; 365-378.

Navarro, M. (1994). Evita. Argentina: Grupo Editorial Planeta. (Versión digitalizada).

Pallarés Pique, M. (2014). Medios de comunicación: ¿espacio para el ocio o agentes de socialización en la adolescencia? Pedagogía Social. Revista Interuniversitaria, 23; 231-252.

Perkowska, M. (2014). Reseña del libro de Valeria Grinberg Pla: Eva Perón. Cuerpo, género, nación. Estudio crítico de sus representaciones en la literatura, el cine y el discurso académico desde 1951 hasta la actualidad. Cuadernos Inter.c.a.mbio sobre Centroamérica y el Caribe, 1, 11; 235-240.

Perón, E. (1951). La razón de mi vida. Argentina: Ediciones Peuser. (Versión digitalizada).

Piñeyro, A. (2011). Blanca Luz Brum, una vida sin fronteras. Maldonado (Uruguay): Botella al mar.

Propp, V. (1981). Morfología del cuento. Madrid: Editorial Fundamentos.

Rosano, S. (2005). Rostros y máscaras de Eva Perón: imaginario populista y representación (Argentina 1951-2003). University of Pittsburgh.

Stam, Robert; Borgoyne, Robert \& Fitterman-Lewis, Sandy (1999). Nuevos conceptos de la teoría 
del cine. Estructuralismo, semiótica, narratología, psicoanálisis, intertextualidad. Barcelona, Editorial Paidós.

Velázquez, T. (2011). Las técnicas de análisis socio semiótico, en Vilches, L. (coord.). La investigación en comunicación. Métodos y técnicas en la era digital. Barcelona: Editorial Gedisa.

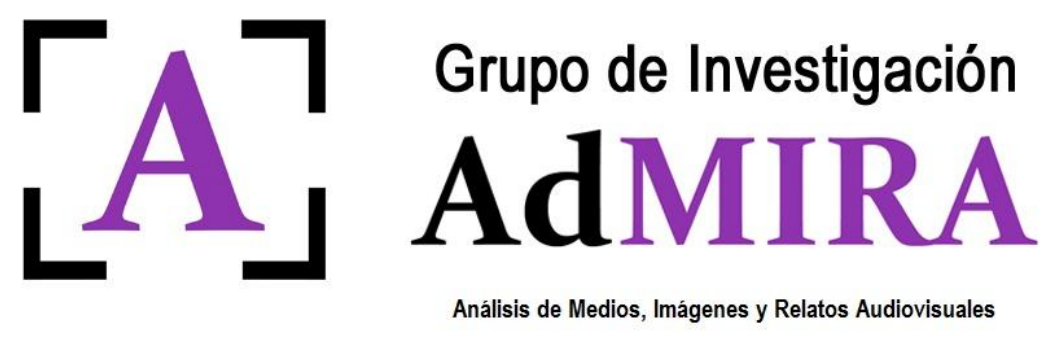

